\title{
CRYOGENIC FREEZING OF SILVER CARP SPERMATOZOA FOR CONSERVATION OF GENE POOL
}

\author{
M. S. Hossain and M. R. I. Sarder* \\ Department of Fisheries Biology and Genetics, Bangladesh Agricultural University \\ Mymensingh-2202, Bangladesh
}

\begin{abstract}
A series of experiments were conducted to develop and standardize the protocols for cryopreservation of sperm of silver carp (Hypophthalmicthys molitrix) with the view to conserve gene pool. Three extenders such as Alsever's solution, urea egg-yolk, egg-yolk citrate, and three cryoprotectants namely DMSO, methanol and ethanol were employed. Cryodiluents were prepared by mixing the cryoprotectants at $10 \%$ concentration of the extenders $(\% \mathrm{v} / \mathrm{v})$. Milt and cryodiluents were mixed at a ratio of 1:9 for Alsever's solution and 1:4 for urea egg-yolk and egg-yolk citrate solutions. Alsever's solution, urea egg-yolk and egg-yolk citrate with DMSO found suitable for cryopreservation of sperm and it produced $81 \pm 2.24 \%, 79 \pm 5.48 \%$ and $74 \pm 4.18 \%$ post-thawed spermatozoan motility respectively. In optimizing milt dilution, five dilution ratios $(1: 2,1: 4,1: 6,1: 9$ and $1: 12)$ were tested and among them 1:9 (milt: cryodiluent) demonstrated the highest post-thaw spermatozoan motility with Alsever's solution $(76.67 \pm 2.89 \%)$ and $1: 4$ produced the same with urea-eggyolk $(73.33 \pm 2.8 \%)$ and egg-yolk citrate $(76.67 \pm 2.89 \%)$. As an optimum cryoprotectant fraction, $10 \%$ concentration was found effective to produce the highest spermatozoan motility for all three extenders. Sperm preserved with Alsever's solution, urea egg-yolk and egg-yolk citrate plus DMSO demonstrated the ability to fertilize eggs and produced hatchlings.
\end{abstract}

Key words : Silver carp, Cryopreservation, Sperm, Fertilization, Hatching

\section{INTRODUCTION}

Silver carp (Hypophthalmichthys molitrix) is an exotic fish of Bangladesh having good nutritional value and adequate rural demand. A $100 \mathrm{~g}$ silver carp contains $20 \mathrm{~g}$ protein, $1.1 \mathrm{~g}$ fat, $11 \mathrm{~g}$ iron, $350 \mathrm{mg}$ calcium and $382 \mathrm{mg}$ phosphorus (Siddiqui and Chowdhury, 1996). Silver carp may attain a weight of $1.5 \mathrm{~kg}$ in first year and $4-5 \mathrm{~kg}$ in the second year. It is a fast-growing species introduced in Bangladesh in 1969 from Hong Kong and contributed $23.36 \%$ to the total culture fish production (DoF, 2007). Among the exotic fishes, silver carp has attracted more attention of ecologists and fishery managers, because of its impressive growth rate and ability to live harmoniously with other carp species. Fish producers ranked Catla catla as the most preferred species followed by $H$.

\footnotetext{
*Corresponding E-mail :- rafiqulsarder@yahoo.com
} 
molitrix, Labeo rohita and Cirrhinus cirrhosus on the basis of market demand and growth rate. Since, silver carp is cultured all over the country and is comparatively cheaper, it is known as poor people's fish.

The seed of silver carp is artificially produced in hatcheries along with other indigenous and exotic carps. About 900 hatcheries (Government and private) have been established to meet the demand of fry and at present approximately $99 \%$ of total seed are produced in the hatcheries (DoF, 2003). However, the quality of seeds has been deteriorated over the years due to inbreeding, hybridization and improper brood stock management (Alam and Khan, 2004). The purity of silver carp is being severely threatened by introgressive hybridization with bighead carp. Cryopreservation of sperm and its use in breeding may play an important role in conserving the genetic purity of the species and its existing gene pool. Production of silver carp fry with high success rate using cryopreserved sperm has been reported (Alvarez et al., 2003). With the view of above facts, attempts have been taken to cryopreserve sperm of silver carp by developing and standardizing cryopreservation protocols through optimizing cryodiluents, milt dilution and cryoprotectant concentration.

\section{MATERIALS AND METHODS}

The experiment was conducted in the Genetics laboratory, mini hatchery and wet laboratory of the Department of Fisheries Biology and Genetics, Bangladesh Agricultural University by using the following methods.

\section{Collection and maintenance of brood fish}

The brood fish weighing about 1.5 - $3.5 \mathrm{~kg}$ were collected from good hatchery sources and reared in the pond in the vicinity of Fisheries Faculty premises with providing quality supplemental feed. Inorganic and organic fertilizers were applied regularly to increase the natural food (Phytoplankton and zooplankton) production.

\section{Collection and observation of milt quality}

Milt was collected from mature males after being induced with pituitary gland (PG) extract. Pure and concentrated white-coloured milt was collected in an eppendrof by applying gentle abdominal pressure and kept on ice. The quality of milt samples were checked under the binocular light microscope at $x 40$ magnification by placing 1-2 $\mu \mathrm{l}$ of milt on a glass slide after addition of 100-200 $\mu$ tap water. Sperm samples containing more than $80 \%$ motility were used.

\section{Preparation of milt for cooling}

For preservation of milt, three extenders, Alsever's solution, urea-egg-yolk and egg-yolk citrate and three cryoprotectants methanol, DMSO (Dimethyl sulphoxide) and ethanol were used. Cryodiluents were prepared by adding 10\% cryoprotectant to $90 \%$ extender $(\% \mathrm{v} / \mathrm{v})$. Milt and cryodiluents were mixed at a ratio of $1: 9$ for Alsever's solution and 1:4 
for urea egg-yolk and egg-yolk citrate solutions. According to Sarder et al. (2006 and 2007), milt sample was first cooled from the ambient temperature $\left(0^{\circ} \mathrm{C}\right)$ to $-4^{\circ} \mathrm{C}$ at a falling rate of $4^{\circ} \mathrm{C}$ per min and then from $-4^{\circ} \mathrm{C}$ to $-80^{\circ} \mathrm{C}$ at a falling rate of $10^{\circ} \mathrm{C}$ per min. After reaching to $-80^{\circ} \mathrm{C}$, samples were removed from the cryochamber and loaded into the canisters and finally placed into the liquid nitrogen $\left(-196^{\circ} \mathrm{C}\right)$ for long-term preservation.

For determining the suitable dilution ratio between milt and cryodiluents, milt was diluted with each of the cryodiluents at five different ratios such as $1: 2,1: 4,1: 6,1: 9$ and $1: 12$. Similarly, five different cryoprotectant concentrations such as $5,10,15,20$ and $25 \%$ were tested for determining its suitable concentration. Fertilization trial was conducted using sperm preserved with Alsever's solution, urea egg yolk and egg yolkcitrate with DMSO.

\section{Collection, fertilization and hatching of eggs}

Eggs were collected from hormone induced (PG plus HCG) female brood by stripping into a plastic bowl immediately after ovulation. Stripped eggs were divided into four batches where each batch contained approximately 1200 eggs; three batches of eggs were fertilized with cryopreserved sperm (sperm preserved with three different cryodiluents) and one batch was fertilized with fresh sperm which was considered as control. Each of the three batches of eggs was fertilized with $12 \times 230 \mu$ of cryopreserved milt i.e. 12 straws were used for each batch and each straw contained $230 \mu \mathrm{l}$ diluted milt. For control, adequate amount of fresh milt was used. After insemination, $5-10 \mathrm{ml}$ of $0.9 \% \mathrm{NaCl}$ solution was added to the egg mass-milt and mixed with a feather for about $1 \mathrm{~min}$. The fertilized eggs were then transferred to incubators for hatching.

\section{Statistical analyses}

The equilibrium and post-thawed motility of sperm were analyzed using two-factor randomized complete block design through computer software package (MSTAT). The fertilization and hatching rates were analyzed using one-way ANOVA followed by Duncan's Multiple Range Test (DMRT).

\section{RESULTS AND DISCUSSION}

\section{Effect of cryodiluent on sperm motility at equilibrium and post-thaw period}

When the motility of sperm was checked at two different periods (equilibrium and postthaw) a positive correlation $(\mathrm{r}=0.973)$ between the equilibrium and post-thaw motility was observed (Fig. 1). ANOVA showed that cryodiluent had significant $(P<0.01)$ effect on the spermatozoan motility at post-thaw period. The extenders and cryoprotectants selected for this experiment were chosen from previous studies (Kumar 1988 and 1989; Alvarez et al., 2003) and among them Alsever's solution, urea egg-yolk and egg-yolk citrate with DMSO produced the highest spermatozoan motility at the equilibrium $(>80 \%)$ and post-thaw periods $(>75 \%)$ (Table 1$)$. DMSO seems to be effective for preservation of sperm and such effectiveness of DMSO with Alsever's solution in $H$. 
molitrix was observed by Alvarez et al. (2003). The three extenders were found to be suitable which could be explained with the fact that they might have specific concentration to balance the osmotic pressure of spermatozoa. The cryoprotective agent is a crucial factor that functions by reducing the thermal shock. DMSO was found more effective than other cryoprotectants, and the reason could be of its more permeability to cells (Whittingham, 1980). DMSO penetrates rapidly into the cellular membrane (Rao, 1989) and brings a quick balance in between the intra- and extra-cellular fluid concentration. The lowest percentage of equilibrium and post-thaw motility was observed in urea egg-yolk with ethanol ( $68 \pm 4.47 \%$ and $54 \pm 4.48 \%$ respectively).

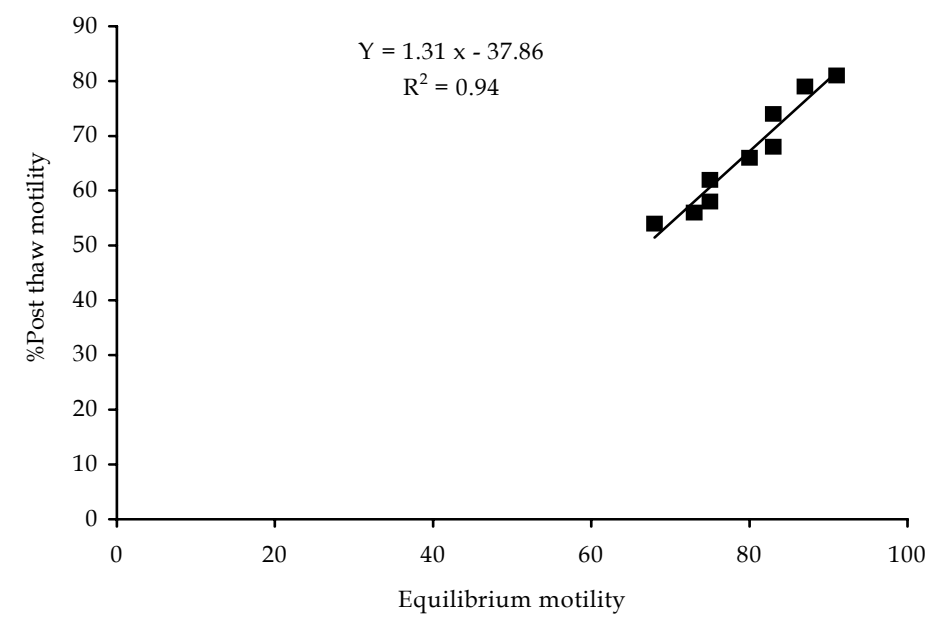

Fig. 1. Correlation between equilibrium and post-thaw motility of sperm of H. molitrix

Table 1. Average equilibrium and post-thaw motility of silver carp sperm mixed with different cryodiluents

\begin{tabular}{l|c|c|c|c}
\hline Extender & Cryoprotectant & Dilution ratio & \multicolumn{2}{|c}{ Motility (\%) } \\
\cline { 4 - 5 } & & & Equilibrium & Post-thaw \\
\hline Alsever's solution & DMSO & $1: 9$ & $91 \pm 2.24^{\mathrm{a}}$ & $81 \pm 2.24^{\mathrm{a}}$ \\
& Ethanol & & $80 \pm 5.00^{\mathrm{d}}$ & $66 \pm 4.18^{\mathrm{c}}$ \\
& Methanol & & $83 \pm 2.74^{\mathrm{c}}$ & $68 \pm 4.47^{\mathrm{c}}$ \\
\hline Urea-egg yolk & DMSO & $1: 4$ & $87 \pm 4.47 \mathrm{~b}$ & $79 \pm 5.48^{\mathrm{ab}}$ \\
& Ethanol & & $68 \pm 4.47 \mathrm{~g}$ & $54 \pm 4.47^{\mathrm{e}}$ \\
& Methanol & & $73 \pm 2.74^{\mathrm{f}}$ & $56 \pm 5.48^{\mathrm{de}}$ \\
\hline Egg-yolk citrate & DMSO & $1: 4$ & $83 \pm 2.74^{\mathrm{c}}$ & $74 \pm 4.18^{\mathrm{b}}$ \\
& Ethanol & & $75 \pm 3.54^{\mathrm{e}}$ & $62 \pm 4.47_{\mathrm{cd}}$ \\
& Methanol & & $75 \pm 3.54^{\mathrm{e}}$ & $58 \pm 4.47^{\mathrm{de}}$ \\
\hline
\end{tabular}

Values with different superscripts (letters) in the same column for A particular cryodiluent differed significantly at $\mathrm{P}<0.05$ 


\section{Effect of dilution ratio on post-thaw sperm motility}

Effects of five dilution ratios $(1: 2,1: 4,1: 6,1: 9$ and $1: 12)$ between milt and cryodiluents on post-thaw motility of sperm were investigated where three extenders viz. Alsever's solution, urea egg-yolk and egg-yolk citrate solutions and three cryoprotectants DMSO, ethanol and methanol were used. The analyses of the results showed that the percent motility of spermatozoa at the post-thawed period was significantly $(\mathrm{P}<0.01)$ higher at 1:9 for Alsever's solution (76 $\pm 2.89 \%)$ and at 1:4 for egg-yolk citrate $(76 \pm 2.89 \%)$ and urea egg-yolk $(73 \pm 2.89 \%)$ solutions with DMSO than other cryoprotectants at the same dilution ratio (Fig. 2).
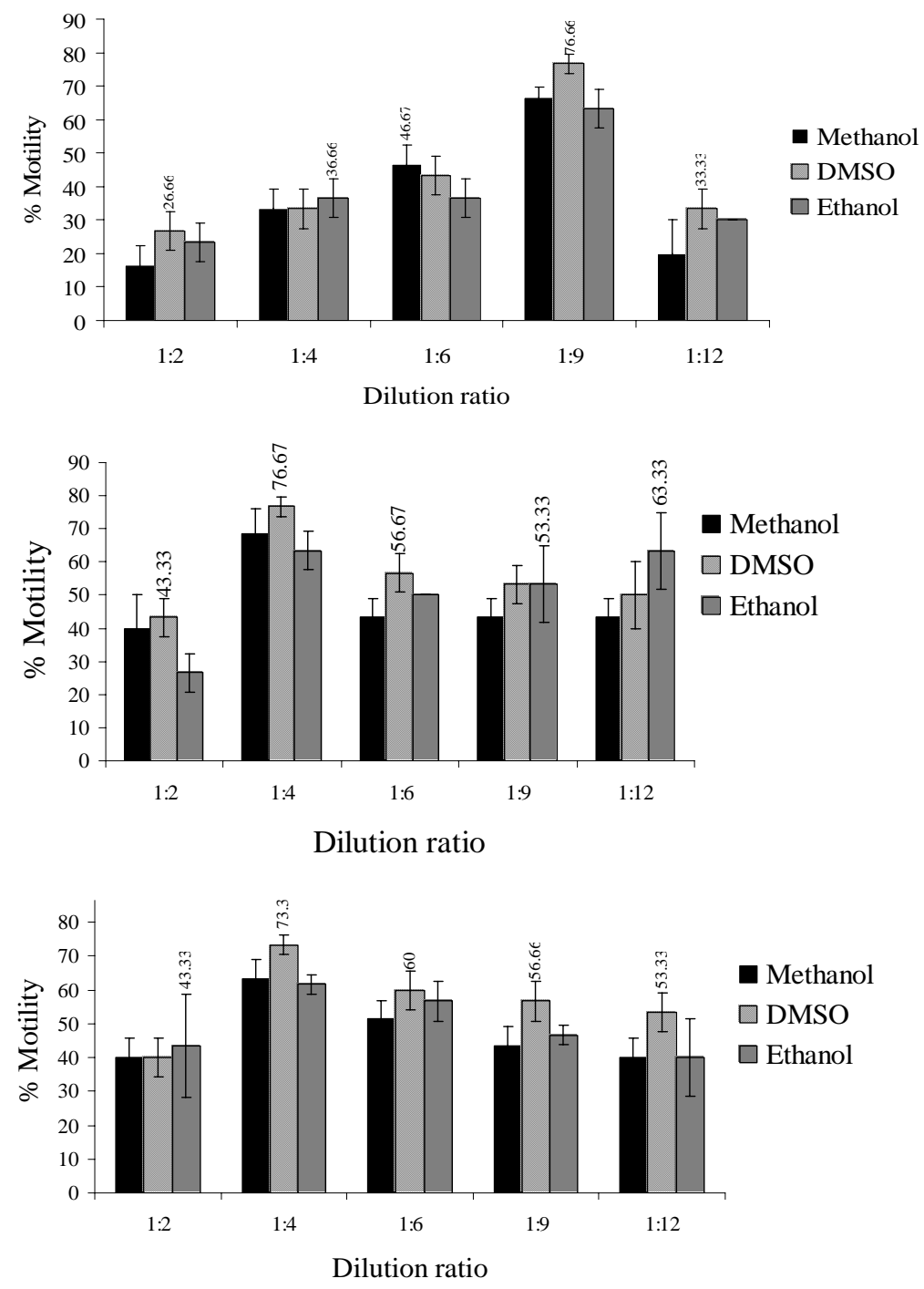

Fig. 2. Effect of different dilution ratios on post-thaw motility of sperm, (a) Alsever's solution

(b) Urea egg-yolk (c) Egg-yolk citrate each with methanol, DMSO and ethanol 
Sin (1974) reported that the survival and degree of motility of silver carp and big head carp sperm were higher at the dilution of $1: 6$ but it became vigorously motile and comparable to the fresh sperm at the dilution ratio of 1:3. In the present study, the survival of the freeze thawed sperm at the dilution ratio of $1: 4$ and $1: 9$ appeared to be highest. The lowest $(1: 2)$ and highest $(1: 12)$ dilution ratios produced the lowest sperm motility. This result did not agree with the findings of Horton et al. (1967) who found that as the dilution of milt of salmon decreased, the degree of motility and the percentage of motile sperm increased. Dreanno et al. (1997) found no significant effect of dilution ratio on post-thawed motility when turbot spermatozoa were diluted at the ratios of $1: 1,1: 2$, $1: 4$ and $1: 9$.

\section{Effects of different cryoprotectant concentrations on post- thaw sperm motility}

When trials were made to optimize cryoprotectant fraction using five different concentrations $(5,10,15,20$ and $25 \%), 10 \%$ concentration found most effective with most of the extenders and it produced significantly $(\mathrm{P}>0.05)$ higher motility than those of other concentrations (Fig. 3). Increase of DMSO concentration beyond $10 \%$ caused a rapid decline in post-thaw motility and its $25 \%$ concentration produced very poor post-thaw motility. Yao et al. (2000) stated that with the increase of DMSO, motility of post-thawed sperm of ocean pot was increased and it reached to the peak at its $20 \%$ (v/v) concentration. They also found that further increase of DMSO above $20 \%$ caused a rapid decline in post-thawed motility and it reached to zero at its 30\% concentration. Similar assumption was postulated by Rana and McAndrew (1989) that the motility could not be initiated when the spermatozoa was suspended in 30\% and 40\% methanol or DMSO.

\section{Effects of cryopreservation on hatching of eggs}

In breeding trials, eggs fertilized with cryopreserved sperm produced $9.70 \pm 7.15$ to 13.75 $\pm 10.13 \%$ hatchling, while fresh sperm produced comparatively higher percentage of hatchling, $20.30 \pm 11.72 \%$ (Table 2). Though sperm preserved with different extenders and cryoprotectants and used for fertilization, sperm preserved with DMSO with either Alsever's solution, urea egg-yolk or egg-yolk citrate produced hatchling. Alvarez et al. (2003) observed that H. molitrix sperm preserved with DMSO plus Alsever's solution for 1 to 365 days yielded hatching rate similar to fresh sperm. Sin (1974) achieved highest fertilization rate of $2.7-5.7 \%$ with diluent composed of inorganic salt, $4.8 \%$ DMSO and $10 \%$ glycerine.

Table 2. Fertilization and hatching of silver carp egg with cryopreserved and fresh sperm

\begin{tabular}{lcc|c}
\hline \multicolumn{1}{c|}{ Cryodiluents } & No. of egg & Fertilization rate (\%) & Hatching rate (\%) \\
\hline Alsever's solution + DMSO & 1200 & $45 \pm 2.89 \mathrm{c}$ & $13.75 \pm 10.13^{\mathrm{a}}$ \\
Urea egg-yolk + DMSO & 1200 & $35 \pm 2.89^{\mathrm{c}}$ & $10.51 \pm 9.76^{\mathrm{a}}$ \\
Egg-yolk citrate + DMSO & 1200 & $34.66 \pm 2.91^{\mathrm{b}}$ & $9.70 \pm 7.15^{\mathrm{a}}$ \\
\hline Control & 1200 & $73.33 \pm 1.67^{\mathrm{a}}$ & $20.30 \pm 11.72^{\mathrm{a}}$ \\
\hline
\end{tabular}

Values in the same column with different superscripts are significantly $(\mathrm{P}<0.05)$ different 


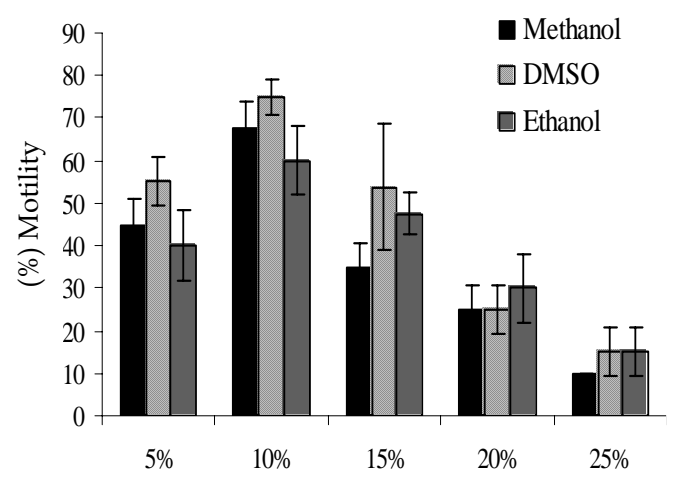

Cryoprotectant percentage

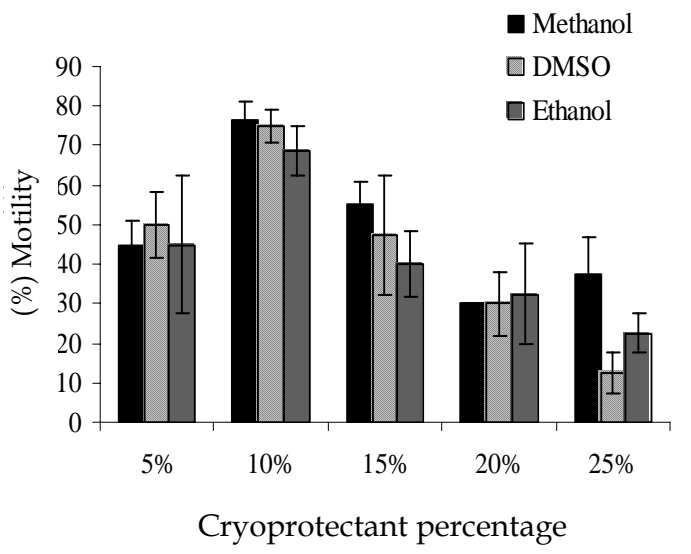

Methanol

$\square$ DMSO

$\square$ Ethanol

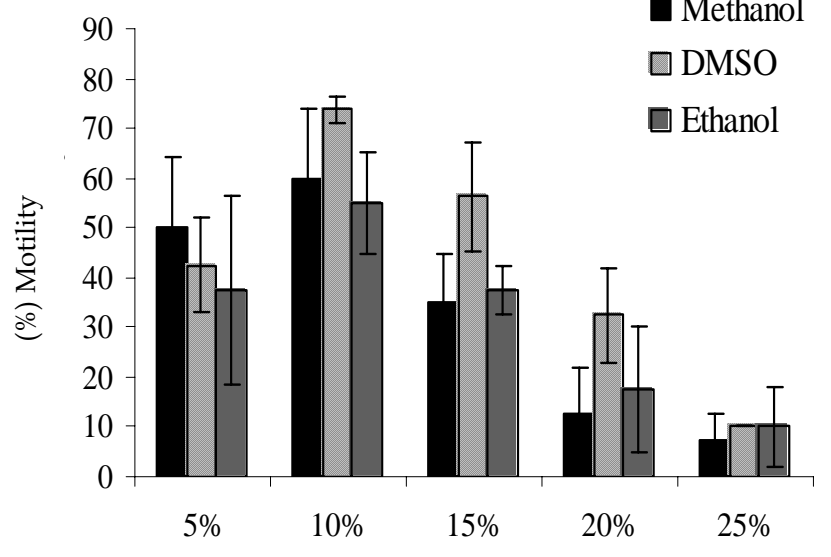

Cryoprotectant percentage

Fig. 3. Effect of different cryoprotectant concentration on post-thaw motility of sperm, (a) Alsever's solution, (b) Urea egg-yolk, (c) Egg-yolk citrate each with methanol, DMSO and ethanol

In the present study fertilization rates of eggs with cryopreserved and fresh sperm were significantly $(\mathrm{P}<0.01)$ different but no significant $(\mathrm{P}>0.05)$ differences in the hatching rates between fresh and frozen spermatozoa were observed. Fertilization and hatching of eggs using cryopreserved sperm was possible but the hatching rates need to be increased through optimizing techniques of thawing of frozen sperm and fertilization.

\section{ACKNOWLEDGEMENT}

The authors would like to thank Ministry of Science and Information and Communication Technology, Government of the People's Republic of Bangladesh for financial support to the project. 


\section{REFERENCES}

Alvarez, B., Fuentes, R., Pimentel, R., Abad, Z., Cabrea, E., Pimentel, E. and Arenal, A. 2003. High fry production rate using post-thaw silver carp (Hypophthalmicthys molitrix) spermatozoa under farming conditions. Aquaculture, 220: 195-201.

Alam, M. S. and Khan, M. M. R. 2004. Preliminary studies on genetic structure of silver carp (Hypophthalmicthys molitrix) and bighead carp (Aristichthys nobilis) sampled from three hatcheries by allozyme marker. Bangladesh J. Fish. (Special Issue, 2004), 27: 28.

DoF, 2003. Fish Fortnight Compendium, Department of Fisheries, Ministry of Fisheries and Livestock, Government of the Peoples Republic of Bangladesh, pp. 110-114.

DoF, 2007. Fisheries Statistical Yearbook of Bangladesh. Department of Fisheries, Ministry of Fisheries and Livestock, Government of the Peoples Republic of Bangladesh, pp. 42.

Dreanno, C., Suquet M., Quemener, L, Cosson,J., Fierville, F., Normant, Y. and Billard, R. 1997. Cryopreservation of turbot, Scophthalmus maximus spermatozoa. Theriogenology, 48: 589-603.

Horton, H. F., Graybill, J. R. and Wu ASH. 1967. Cryogenic preservation of viable fish sperm. Contract Completion Rep., Dep. Fish. Wildl., Oregon State Univ., Corvallis, Oreg., 93 p.

Kumar, K. 1988. A comparative study of various extenders for cryopreservation of carp spermatozoa. Indian J. Anim. Sci., 58(11): 1355-1360.

Kumar, K. 1989. Studies on cryogenic preservation of carp spermatozoa. Fish Genetics in India, (Eds.) Das \& Jhingram, 199-206 pp.

Rana, K.J. and McAndrew BJ. 1989. The viability of cryopreserved Tilapia spermatozoa. Aquaculture, 76: 335-345.

Rao, K. G. 1989. Cryopreservation of carp sperm. In: Das and Jhingran (eds.) Fish Genetics in India, Today and Tomorrows Printers and Publishers, New Delhi. pp. 193-198.

Sarder, M. R. I., Hossain, M. S., Al-Mamun, M. M. and Rashid, M. H. O. 2007. Growth and survival of fry of common carp (Cyprinus carpio) produced with cryopreserved sperm. The Bang. Vet., 24(1): 79-86.

Sarder, M. R. I., Rafiquzzaman, S. M., Islam, M. S. and Sultana, R. 2006. Cryopreservation of spermatozoa of tilapia, Oreochromis niloticus L. by optimizing different factors. J. Asiat. Soc. Bangladesh, Sci., 32(1): 89-96.

Siddiqui, K. and Choudhury, S. N. 1996. Matsya- Pukure mach chash manual. National Institute of Local Government (publishers), Agargaon, Dhaka, 606 p.

Sin, A. W. 1974. Preliminary results on cryogenic preservation of sperm of silver carp (Hypophthalmichthys molitrix) and bighead carp (Aristichthys nobilis). Hong Kong Fish. Bull., 4: 33-36.

Whittingham, D. G. 1980. Principles of embryo preservation. In: Low Temperature Preservation in Medicine and Biology. (Ashwood-Smith MJ and Farrant J, Ed.) Medical Limited, London, England. pp. 65-83.

Yao, Z, Crim, L. W., Richardson, G. F. and Emerson, C. J. 2000. Motility, fertility and ultra structural changes of ocean pout (Macrozoarces americanus L.) sperm after cryopreservation. Aquaculture, 181: 361-375. 